\title{
PENGARUH FASILITAS PERPUSTAKAAN TERHADAP BUDAYA BACA
}

\author{
Zulkifli R. Moo $^{1)}$, irina popoi ${ }^{2)}$, melizubaida mahmud ${ }^{3)}$ \\ Universitas Negeri Gorontalo, \\ E;mail :zulkiflirmoo@gmail.com
}

\begin{abstract}
ABSTRAK
Penelitian ini bertujuan untuk mengetahui seberapa besar pengaruh fasilitas perpustakaan terhadap budaya baca siswa kelas XI IPS di SMA Negeri 1 Kota Gorontalo..Metode yang digunakan dalam penelitian ini adalah metode kuantitatif. Sampel dalam penelitian ini berjumlah 41 responden. Tehnik pengumpulan data ialah observasi, kuesioner, dan dokumentasi. Adapun teknik analisis data menggunakan analisis regresi linear sederhana. Hasil penelitian ini menunjukan bahwa terdapat pengaruh positif fasilitas perpustakaan terhadap budaya baca siswa kelas XI IPS di SMA Negeri 1 Kota Gorontalo. Hal ini ditunjukan dengan model analisis regeresi adalah $\hat{Y}=3,605+0,752 X+\varepsilon$. Dengan besar pengaruh fasilitas Kelas XI IPS Di SMA Negeri 1 Kota Gorontalo". Program Studi Pendidikan Ekonomi Konsentrasi Pendidikan Ekonomi Akuntansi, Jurusan Pendidikan Ekonomi, Fakultas Ekonomi, Universitas Negeri Gorontalo. Dibawah bimbingan perpustakaan terhadap budaya baca siswa mencapai $35,7 \%$ dan sisanya $64,3 \%$ budaya baca siswa dipengaruhi oleh variabel lain.
\end{abstract}

Kata kunci : Fasilitas Perpustakaan, Budaya Baca Siswa

\begin{abstract}
ABTRACT
This study aims to determine how much influence library facilities have on the reading culture of students of class XI IPS in SMA Negeri 1 Gorontalo City. The method used in this research is quantitative method. The sample in this study amounted to 41 respondents. Data collection techniques are observation, questionnaire, and documentation. The data analysis technique uses simple linear regression analysis. The results of this study indicate that there is a positive effect of library facilities on the reading culture of students of class XI IPS in SMA Negeri 1 Gorontalo City. This is indicated by the regression analysis model is $\hat{\mathrm{Y}}=3.605+0.752 \mathrm{X}+\varepsilon$. With a large influence on the Class XI IPS facilities in SMA Negeri 1 Gorontalo City ". Economic Education Study Program Concentration in Economic Education Education, Department of Economic Education, Faculty of Economics, Gorontalo State University. Under the guidance of the library on student reading culture reached $35.7 \%$ and the remaining $64.3 \%$ of students' reading culture was influenced by other variables.
\end{abstract}

Keywords: Library Facilities, Student Reading Culture 


\section{PENDAHULUAN}

Fasilitas perpustakaan merupakan alat kelengkapan yang langsung berhubungan dengan mutu pendidikan dalam rangka mencapai tujuannya, karena mempengaruhi efisiensi proses belajar mengajar. Perpustakaan memungkinkan murid memperoleh kesempatan memperluas dan memperdalam pengetahuan dan pandangan masing-masing. Dan dengan adanya fasilitas perpustakaan sebagai sarana dan prasarana sekolah yang memadai akan diikuti peningkatan prestasi belajar (Nadari Nawawi, 2006: 144).Fasilitas perpustakaan, terutama perpustakaan sekolah harus diciptakan sedemikian rupa agar membantu kemudahan untuk siswa yang memakai perpustakaan supaya mendapatkan kenyamanan secara maksimal. Melalui perpustakaan siswa dapat menambah wawasan dan pengetahuan yang dimiliki, sehingga dapat menunjang proses belajar mengajar. Selain perpustakaan disetiap kelas juga terdapat sudut literasi yang merupakan program pemerintah, dimana dengan adanya sudut literasi ini dapat meningkatkan budaya baca siswa.

Budaya membaca itu sendiri adalah kegiatan positif rutin yang baik dilakukan untuk melatih otak untuk menyerap apa-apa saja informasi yang terbaik diterima seseorang dalam kondisi dan waktu tertentu. Sumber bacaan bisa diperoleh dari buku, surat kabar, tabloid, internet, dan sebagainya. Dianjurkan untuk membaca berbagai hal yang positif. Informasi yang baik akan membuat hasil yang baik pula bagi anda (Rozin, 2008).

Membaca dipandang sebagai satu kegiatan yang amat strategi dan mendasar dalamperkembangan kepribadian atau psikologi pada setiap diri manusia. Kenyataan ini dapat dilihat dari kebiasaan seseorang, bahwa apa yang dibaca akan berpengaruh terhadap pola pikir dan perilakunya pada kehidupan sehari-hari sebabnya setiap siswa dianjurkan membaca. Membaca bukanlah kewajiban yang datang dari luar dan harus dilakukan dengan terpaksa, melainkan sebuah kebutuhan yang timbul dari dalam diri dan tentu saja akan dilakukan dengan senang hati.

Berdasarkan observasi awal yang peneliti lakukan di perpustakaan SMA Negeri 1 Gorontalo, menunjukan bahwa budaya baca siswa masih sangat minim. Terdapat beberapa permasalahan yang muncul yaitu, masih kurangnya motivasi guru pada siswa dalam meningkatkan budaya baca, dan siswa kelas XI IPS yang mengunjungi perpustakaan < 50\% siswa yaitu dari jumlah keseluruhan 491 siswa hanya 246 yang mengunjungi perpustakaan.

Kurangnya pendukung fasilitas perpustakan berupa koleksi buku yang belum lengkap, hendaknya meja dan kursi baca ditambah lagi dan ditata rapi. Hal ini akan mempengaruhi minat siswa untuk mengunjungi perpustakaan. Oleh karena itu, pihak perpustakan perlu menyiapkan fasilitas perpustakaan yang nyaman.

Karena perpustakaan mempunyai peran yang sangat penting untuk melestarikan budaya baca siswa. Berdasarkan penjelasan diatas peneliti ingin mengetahui apakah fasilitas perpustakaan dapat mempengaruhi budaya baca siswa. 


\section{METODE}

Penelitian ini menggunakan metode kuantitatif, Metode kuantitatif merupakan metode penelitian yang digunakan untuk menggambarkan masalah yang terjadi pada masa sekarang atau yang sedang berlangsung, bertujuan untuk mendeskripsikan apaapa yang terjadi sebagaimana mestinya pada saat penelitian dilakukan (Sugiyono, 2017). Metode ini bertujuan memberikan gambaran tentang pengaruh fasilitas perpustakaan terhadap budaya baca siswa kelas XI IPS di SMA Negeri 1 Kota Gorontalo.

Populasi adalah wilayah generalisasi yang terdiri atas: obyek/subyek yang mempunyai kualitas dan karakteristik tertentu yang di tetapkan oleh peneliti untuk di pelajari dan kemudian di tarik kesimpulannya (Sugiyono. 2017:117). Berdasarkan penelitian tersebut, maka yang menjadi populasi dalam penelitian ini adalah seluruh siswa kelas XI IPS di SMA Negeri 1 Kota Gorontalo yang terdiri dari 5 kelas, yaitu: kelas XI IPS $1=34$ siswa, kelas XI IPS $2=32$ siswa, kelas XI IPS $3=31$, kelas XI IPS $4=34$, dan kelas XI IPS $5=32$ siswa. Jadi, jumlah seluruh siswa yang terdapat di kelas XI IPS SMA Negeri 1 Kota Gorontalo adalah 162 siswa.

Sampel adalah bagian dari jumlah dan karakteristik yang dimiliki oleh populasi tersebut. Bila populasi besar, dan peneliti tidak mungkin mempelajari semua yang ada pada populasi, misalnya karena keterbatasan dana, tenaga dan waktu, maka peneliti dapat menggunakan sampel yang diambil dari populasi itu (Sugiyono, 2015:118). Apabila populasi penelitian berjumlah kurang dari 100 maka sampel yang diambil adalah semuanya, namun apabila populasi penelitian berjumlah lebih dari 100 maka sampel dapat diambil antara $10-15 \%$ atau $20-25 \%$ atau lebih.

Berdasarkan hal tersebut di atas, maka yang menjadi sampel penelitian ini adalah $25 \%$ dengan jumlah 41 responden. Tehnik pengumpulan data yang digunakan adalah angket, dokumentasi, dan observasi. Sedangkan teknik pengujian menggunakan uji validitas dan sama, akan menghasilkan data yang sama. Perhitungan reliabilitas instrumentmenggunakan rumus korelasi alpha cronbach, yaitu: reliabilitas, normalitas, dan regresi linear sederhana.

\section{HASIL DAN PEMBAHASAN}

Hasil analisis data menunjukkan bahwa dari segi ketepatan dalam mengukur 15 pertanyaan yang digunakan dalam mengukur Fasilitas Perpustakaan. Seluruh pertanyaan telah memiliki ketepatan yang baik. Hasil analisis data menunjukkan bahwa dari segi ketepatan dalam mengukur 15 pertanyaan yang digunakan dalam mengukur Budaya Baca. Seluruh pertanyaan telah memiliki ketepatan yang baik.

Reliability Statistics

\begin{tabular}{c|c}
\hline Cronbach's Alpha & N of Items \\
\hline, 880 & 15 \\
\hline
\end{tabular}

Nilai koefisien reliabilitas untuk variabel Budaya Baca Siswa dari hasil uji tersebut sebesar 0.880.Nilai koefisien reliabilitas ini lebih besar dari 
0.6.Sehinggamenunjukkan hasil pengukuran yang dihasilkan oleh instrumen yang digunakan menunjukkan konsistensi yang cukup baik pada setiap responden. Atau dengan kata lain, presepsi responden mengenai pertanyaan yang digunakan sudah homogen.

\section{Pengujian Normalitas Data}

One-Sample Kolmogorov-Smirnov Test

\begin{tabular}{l|c}
\hline & Unstandardiz ed Residual \\
\hline $\mathrm{N}$ & 41 \\
\hline Test Statistic &, 060 \\
\hline Asymp. Sig. (2-tailed) &, 200 \\
\hline
\end{tabular}

Berdasarkan Hasil analisis di atas menunjukkan nilai signifikansi untuk pengujian normalitas data adalah sebesar 0,200. Jika dibandingkan dengan nilai alpha yang digunakan $(0,05)$ maka nilai signifikansi yang diperoleh ini masih lebih besar sehingga Ho diterima. Dengan demikian dapat disimpulkan bahwa data variabel dependen (budaya baca siswa) telah berdistribusi normal.

Pengujian Model Regresi Secara Keseluruhan

ANOVA ${ }^{a}$

\begin{tabular}{|c|c|c|c|c|c|}
\hline Model & Sum of Squares & $\mathrm{df}$ & Mean Squar e & & \\
\hline Regressi on & 2043,465 & 1 & 2043,465 & \multirow{3}{*}{21,676} & \multirow{3}{*}{, $000 b$} \\
\hline Residual & 3676,583 & 39 & \multirow{2}{*}{94,271} & & \\
\hline Total & 5720,049 & 40 & & & \\
\hline
\end{tabular}

a. Dependent Variable: Budaya Baca

b. Predictors: (Constant), Fasilitas Perpustakaan

Dari hasil di atas didapat nilai F-hitung sebesar 21,676. Adapun nilai F-tabel pada tingkat signifikansi 5\% dan derajat bebas pembilang (df1) sebesar k (jumlah variabel bebas $)=1$ dan derajat bebas penyebut (df2) sebesar $n-k-1=41-1-1=39$ adalah sebesar 4,09. Jika kedua nilai $\mathrm{F}$ ini dibandingkan, maka nilai F-hitung yang diperoleh jauh lebih besar F- tabel sehingga Ho ditolak.

Pengujian Regresi Secara Parsial

\section{Coefficients $^{\mathrm{a}}$}

\begin{tabular}{l|c|c|c|c|c}
\multicolumn{1}{c|}{ Model Summary $^{\mathbf{b}}$} & \multicolumn{2}{|c|}{$\begin{array}{c}\text { Unstandardiz ed } \\
\text { Coefficients }\end{array}$} & $\begin{array}{c}\text { Standardi zed } \\
\text { Coefficient s }\end{array}$ & & \\
\cline { 2 - 4 } & $\mathrm{B}$ & Std. Error & Beta & & \\
\hline 1(Const ant) & 3,605 & 9,076 & &, 397 &, 693 \\
Fasilitas perpustakaar &, 752 &, 162 &, 598 & 4,656 &, 000 \\
\hline
\end{tabular}


Dari output di atas dapat dilihat nilai t-hitung yang diperoleh untuk variable fasilitas perpustakaan adalah sebesar 4,656. Dengan menggunakan tingkat signifikansi sebesar 5\% dan nilai df sebesar $\mathrm{n}-\mathrm{k}-1=41-1-1=39$ diperoleh nilai t-tabel sebesar 2,023. Jika dibandingkan dengan nilai t-hitung yang diperoleh sebesar 4,656 maka nilai t-hitung yang diperoleh masih lebih besar dari nilai t-tabel sehingga Ho ditolak. Dengan demikian pada tingkat kepercayaan $95 \%$ dapat disimpulkan bahwa fasilitas perpustakaan berpengaruh terhadap budaya baca.

\begin{tabular}{c|c|c|c|c}
\hline Model & $\mathrm{R}$ & $\mathrm{R}$ Square & $\begin{array}{c}\text { Adjusted } \\
\mathrm{R} \text { Square }\end{array}$ & Std. Error of the Estimat e \\
\hline 1 &, $598^{\mathrm{a}}$ &, 357 &, 341 & 9,709 \\
\hline
\end{tabular}

Berdasarkan hasil estimasi model persamaan regresi yang telah dilakukan, maka diperoleh nilai koefisien determinasi $\mathrm{R}^{2}$ sebesar 0,357. Nilai ini berarti bahwa sebesar 35,7\% variabel budaya baca siswa Kelas XI IPS di SMA Negeri 1 Kota Gorontalo dipengaruhi oleh fasilitas perpustakan, sedangkan sisanya sebesar 64,3\% dipengaruhi oleh variabel lain.

\section{PEMBAHASAN}

Hasil analisis yang telah dilakukan menunjukkan pengaruh yang positif dari fasilitas perpustakaan terhadap budaya baca siswa kelas XI IPS di SMA Negeri 1 Kota Gorontalo. Hal ini berdasarkan pada hasil pengujian F-hitung untuk variabel budaya baca yang lebih besar dari F-tabel sehingga H0 ditolak. Ini menunjukkan bahwa semakin baik fasilitas di perpustakaan maka budaya baca siswa semakinmeningkat.

Budaya baca siswa adalah keinginan dan kemauan kuat untuk selalu membaca setiap kesempatan atau selalu mencari kesempatan untuk membaca. Budaya baca siswa dipengaruhi oleh beberapa faktor diantaranya faktor individu (internal) dan lingkungan (eksternal). Salah satu faktor eksternal yang dapat mempengaruhi budaya baca siswa adalah fasilitas perpustakaan.

Fasilitas perpustakaan merupakan segala sesuatu yang dipergunakan dan dinikmati guna menunjang pengorganisasian koleksi buku pustaka dan terbitan lain yang diatur sesuai dengan perlengakapan dan peralatan yang ada serta tata susunan dalam suatu ruangan yang nyaman. Fasilitas yang tersedia di perpustakaan SMA Negeri 1 Kota Gorontalo terdiri dari koleksi buku, meja, kursi, ruang baca, komputer, AC, dan lain-lain.

Berdasarkan penjelasan dan deskripsi hasil penelitian di atas maka diperoleh pengaruh fasilitas perpustakaan terhadap budaya baca siswa kelas XI IPS di SMA Negeri 1 Kota Gorontalo. Dengan demikian, sebelum melakukan pengujian hipotesis yang telah ditetapkan, pertama-tama peneliti mengadakan pengujian normalitas data yang telah terkumpul dari responden. Pengujian normalitas data dimaksudkan apakah data tersebut berdistribusi normal atau tidak, sehingga dapat digunakan inti pengujian berikutnya. Dari hasil pengujian normalitas data baik variabel X (Fasilitas Perpustakaan) maupun variabel Y (Budaya Baca) benar-benar berdistribusi normal. 
Adapun hasil analisis regresi menunjukkan terdapat pengaruh positf dari fasilitas perpustakaan terhadap budaya baca. Koefisien regresi yang positif menunjukkan semakin baik fasilitasperpustakaan maka semakin baik pula budaya baca siswa. Namun sebaliknya jika fasilitas perpustakaan tidak baik dan tidak mendukung maka budaya baca siswa dapat menurun. Besar pengaruh dari fasilitas perpustakaan terhadap budaya baca siswa dalam berpresentase sebesar 35,7\%,sedangkan sisanya sebesar $64,3 \%$ variaabel budaya baca siswa dipengaruhi oleh faktor lain seperti motivasi dari guru, lingkungan dan teman sebaya.

\section{KESIMPULAN}

Dari penelitian analisis yang telah dilakukan maka peneliti mengambil kesimpulan bahwa terdapat pengaruh yang positif fasilitas perpustakaan terhadap budayabaca siswa. Semakin baik pengelolaan fasilitas akan mampu meningkatkan budaya baca siswa. Besar pengaruh fasilitas perpustakaan terhadap budaya baca siswa mencapai $35,7 \%$ sedangkan sisanya sebesar $64,3 \%$ dipengaruhi oleh faktor lain seperti motivasi dari guru, lingkungan, dan teman sebaya.

\section{DAFTAR PUSTAKA}

Moenir. 2001.Manajemen Pelayanan Umum di Indonesia. Jakarta: PT Bumi Aksara.

Nawawi, Nadari. 2006. Organisasi sekolah dan pengelolaan kelas. Jakarta: gunung agung. Rozin. 2008. Budaya Membaca. (online) (http://www.rozin.com/index.php?option=comcontent\&task=view\&id=222\&ite

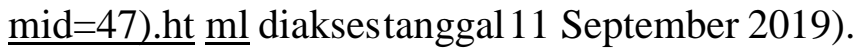

Sitepu, B.P. 2011. Pengembangan Sumber Belajar. Jakarta: Rajawali Press

Sugiyono. 2017. Metode Penelitian (Kuantitatif, Kualitatif, $R \& D$ ).Alfabeta, Bandung.

Supriyanto (Ed). 2006. Aksentuasi Perpustakaan dan Pustakawan. Jakarta: Ikatan PustakawanIndonesia

Sutarno. 2006. Manajemen Perpustakaan Suatu PendekatanPraktik.Jakarta: Sagung Seto

Wikipedia. 2011. Pengertian Budaya Baca. (online) (http://id.wikipedia.org/wiki/ budaya.html. Diakses tangggal 11 September 2019) 